www.jmscr.igmpublication.org

Impact Factor (SJIF): 6.379

Index Copernicus Value: 71.58

ISSN (e)-2347-176x ISSN (p) 2455-0450

crossref DOI:_https://dx.doi.org/10.18535/jmscr/v6i5.58

\author{
Dournal Of Medical Science And Clinical Research \\ IGM Publication \\ An Official Publication of IGM Publication
}

\title{
Relationship between Serum Vitamin D Level and Disease Activity in Rheumatoid Arthritis
}

\author{
Authors \\ Dr A.C. Gupta, Dr Arvind Kumar*, Dr A.K. Mishra, Dr Prem Singh \\ G.S.V.M. Medical College, Kanpur, U.P. India \\ *Corresponding Author \\ Dr Arvind Kumar \\ Add: New Type 4/25, I D H Campus, G S V M Medical College, Kanpur, U.P. India, PIN 208002
}

\begin{abstract}
Introduction: Vitamin $D$ is a fat soluble vitamin. Main source of vitamin $D$ is de novo synthesis in the skin by ultraviolet $B$ rays of sunlight. The active metabolite of vitamin $D$ is the 1,25-dihydroxyvitaminD3(1,25(OH)2 D3), which is regulator of bone and calcium metabolism. It also exerts immunomodulation effect via the nuclear vitamin D Receptor (VDR) expressed in antigen-presenting cells (APC) and activated T/B cells. Rheumatoid arthritis (RA) is an immune-mediated disease, mainly driven by Th1 cells. The characteristic features of the disease are erosive arthritis and joint destruction leading to severe disability and increased mortality. RA affects about 24.5 million people as of 2015. This is between 0.5 and 1\% of adults with 5 per 100,000 people newly developing the condition each year. Although the etiology of RA is unknown, various studies suggest that many environmental and genetic factors are responsible for development of RA. A recent study showed the association of dietary and supplemental vitamin $D$ with $R A$, higher intake of vitamin $D$ was inversely associated with risk of RA. RA is an inflammatory disease characterized by flares and remissions, flares being characterized by pain and swelling of the joints.. Vitamin D deficiency is also known to be associated with diffuse musculoskeletal pain.
\end{abstract}

Aim: To assess the level of serum vitamin D level in patients of Rheumatoid Arthritis and to establish relationship between serum vitamin $D$ level and disease activity in RA.

Method: Forty patients of RA fulfilling 2010 revised criteria of American college of Rheumatology of RA classification and forty healthy controls were included in the study. Serum vitamin D levels were measured. Disease activity was assessed by DAS-28 score.

Results: Ninety five percent of RA patients were either vitamin $D$ deficient or insufficient while only fifty percent of healthy controls were either vitamin $D$ deficient or insufficient ( $p$ value $<0.05)$. Mean serum vitamin $D$ level of patients of $R A$ was $(16.00 \pm 8.91 \mathrm{ng} / \mathrm{ml})$ while mean serum vitamin D level of healthy controls was $(31.5 \pm 14.34 \mathrm{ng} / \mathrm{ml})$ and this difference was statistically highly significant $(p<0.001)$. The prevalence of vitamin $D$ deficiency and insufficiency in patients of $R A$ is $62.5 \%$ and $32.5 \%$ respectively. We concluded vitamin $D$ deficiency is highly prevalent in RA patients and is inversely related with disease activity of RA. There were 6 patients of RA in low disease activity group (DAS 28 score < 3.2) and the mean serum vitamin D level in this group was 30.5 $99.81 \mathrm{ng} / \mathrm{ml}$. There were 18 RA patients in moderate disease activity group (DAS 28 score $3.2-5.1)$ and the mean serum vitamin D levels were $16.7 \pm 5.97 \mathrm{ng} / \mathrm{ml}$. There were 16 RA patients in high disease activity group (DAS 28 score >5.1) and the mean serum $25(O H)$ vitamin $D$ level was $9.60 \pm 4.30 \mathrm{ng} / \mathrm{ml}$. Patients with high disease activity had significantly lower vitamin D levels in comparison to patients with low or moderate disease activity $(p<0.001)$.

Conclusion: Serum vitamin D levels were significantly low in RA patients than in healthy controls. Vitamin D deficiency was seen in significantly higher no. of patients and there is inverse relation between serum vitamin D levels and disease activity.

Keywords: Serum Vitamin D level, Rheumatoid Arthritis (RA), Disease Activity. 


\section{Introduction}

Vitamin D is a steroid hormone involved in bone and calcium metabolism. It is involved in the regulation of calcium homeostasis, as it regulates calcium absorption from the gastrointestinal system. The hormone is synthesized in the skin by the action of ultraviolet radiation. Vitamin D has extra-skeletal effects as well. The non classical actions of vitamin D are currently under discussion. Vitamin D has been found to have immunomodulatory actions. Vitamin D deficiency has been shown to be correlated with the appearance of autoimmune diseases, such as diabetes mellitus type 1 and multiple sclerosis. 1,25-Dihydroxyvitamin $\mathrm{D}(1,25[\mathrm{OH}] 2 \mathrm{D})$ is the major steroid hormone involved in mineral ion homeostasis regulation. Vitamin D and its metabolites are hormones and hormone precursors rather than vitamins, because in the proper biologic setting, they can be synthesized endogenously in response to ultraviolet radiation.

Vitamin D from plant sources is in the form of vitamin D2, whereas that from animal sources is vitamin D3. These two forms have equivalent biologic activity and are activated equally well by the vitamin D hydroxylases in humans. Vitamin D enters the circulation, whether absorbed from the intestine or synthesized cutaneously, bound to vitamin D-binding protein, an $\alpha$-globulin synthesized in the liver. Vitamin $D$ is subsequently hydroxylated in the liver by cytochrome P450-like enzymes in the mitochondria and microsomes. The activity of this hydroxylase is not tightly regulated, and the resultant metabolite, 25-hydroxyvitamin D $(25[\mathrm{OH}] \mathrm{D})$, is the major circulating and storage form of vitamin D. Approximately $88 \%$ of $25(\mathrm{OH}) \mathrm{D}$ circulates bound to the vitamin Dbinding protein, $0.03 \%$ is free, and the rest circulates bound to albumin. The half-life of $25(\mathrm{OH}) \mathrm{D}$ is approximately $2-3$ weeks; however, it is shortened dramatically when vitamin D-binding protein levels are reduced, as can occur with increased urinary losses in the nephrotic syndrome.
The second hydroxylation, required for the formation of the mature hormone, occurs in the kidney. The 25 -hydroxyvitamin D-1 $\alpha$-hydroxylase is a tightly regulated cytochrome P450-like mixed function oxidase expressed in the proximal convoluted tubule cells of the kidney. PTH and hypophosphatemia are the major inducers of this microsomal enzyme, whereas calcium, FGF23, and the enzyme's product, $1,25(\mathrm{OH}) 2 \mathrm{D}$, repress it. The 25-hydroxyvitamin D-1 $\alpha$-hydroxylase is also present in epidermal keratinocytes, but keratinocyte production of $1,25(\mathrm{OH}) 2 \mathrm{D}$ is not thought to contribute to circulating levels of this hormone. In addition to being present in the trophoblastic layer of the placenta, the $1 \alpha$ hydroxylase is produced by macrophages associated with granulomas and lymphomas. In these latter pathologic states, the activity of the enzyme is induced by interferon $\gamma$ and TNF- $\alpha$ but is not regulated by calcium or $1,25(\mathrm{OH}) 2 \mathrm{D}$; therefore, hypercalcemia, associated with elevated levels of $1,25(\mathrm{OH}) 2 \mathrm{D}$, may be observed.

The major pathway for inactivation of vitamin $\mathrm{D}$ metabolites is an additional hydroxylation step by the vitamin D 24-hydroxylase, an enzyme that is expressed in most tissues. 1,25(OH)2D is the major inducer of this enzyme; therefore, this hormone promotes its own inactivation, thereby limiting its biologic effects.

The Institute of Medicine has defined vitamin D sufficiency as a vitamin D level $>50 \mathrm{nmol} / \mathrm{L}$ (>20 $\mathrm{ng} / \mathrm{mL}$ ), although higher levels may be required to optimize intestinal calcium absorption in the elderly and those with underlying disease states. Vitamin D deficiency leads to impaired intestinal absorption of calcium, resulting in decreased serum total and ionized calcium values. This hypocalcemia results in secondary hyperparathyroidism, a homeostatic response that initially maintains serum calcium levels at the expense of the skeleton. Due to the PTH-induced increase in bone turnover, alkaline phosphatase levels are often increased. In addition to increasing bone resorption, PTH decreases urinary calcium excretion while promoting phosphaturia. 
This results in hypophosphatemia, which exacerbates the mineralization defect in the skeleton. With prolonged vitamin D deficiency resulting in osteomalacia, calcium stores in the skeleton become relatively inaccessible, since osteoclasts cannot resorb unmineralized osteoid, and frank hypocalcemia ensues. Because PTH is a major stimulus for the renal 25(OH)D $1 \alpha$ hydroxylase, there is increased synthesis of the active hormone, 1,25(OH)2D. Paradoxically, levels of this hormone are often normal in severe vitamin $\mathrm{D}$ deficiency. Therefore, measurements of $1,25(\mathrm{OH}) 2 \mathrm{D}$ are not accurate reflections of vitamin $\mathrm{D}$ stores and should not be used to diagnose vitamin $\mathrm{D}$ deficiency in patients with normal renal function. It also exerts immunomodulation via the nuclear vitamin $D$ Receptor (VDR) expressed in antigen-presenting cells (APC) and activated T/B cells. Main target of vitamin $\mathrm{D}$ immunomodulation are the dendritic cells (DCs) as indicated by inhibition of DC differentiation and maturation. This ultimately leads to vitamin D induced inhibition of DCdependent T-cell activation. VDR agonists also inhibits the T-cell production of IL-17 which is a pro-inflammatory cytokine produced by Th17 cells in models of organ-specific autoimmunity in the brain, synovium, heart, and intestines. The net effect of the vitamin $D$ is an enhancement of innate immunity with multifaceted regulation of adaptive immunity.

In RA pathogenic mechanisms of synovial inflammation are likely to result from a complex interplay of genetic, environmental, and immunologic factors that produces dysregulation of the immune system and a breakdown in selftolerance. Anti-CCP antibodies are directed against deaminated peptides, which result from posttranslational modification by the enzyme PADI4. They recognize citrulline - containing regions of several different matrix proteins, including filaggrin, keratin, fibrinogen, and vimentin, and are present at higher levels in the joint fluid compared to the serum. People who smoke display higher citrullination of proteins in bronchoalveolar fluid than those who do not smoke. Thus, it has been speculated that long-term exposure to tobacco smoke might induce citrullination of cellular proteins in the lung and stimulate the expression of a neoepitope capable of inducing self-reactivity, which in turns, leads to formation of immune complexes and joint inflammation. The role of $\mathrm{T}$ lymphocytes as well as that of B lymphocytes in the pathogenesis of RA has been further proved by the therapeutic efficacy of methods affecting both $\mathrm{T}$ and $\mathrm{B}$ lymphocytes, namely the biological agents. Vitamin D deficiency may increase the risk for the development of RA. Recently, the role of vitamin $\mathrm{D}$ deficiency in the pathogenesis of RA, as well as the relationship between vitamin $\mathrm{D}$ deficiency and the activity of RA is discussed. RA is an inflammatory disease characterized by flares and remissions, flares being characterized by pain and swelling of the joints. Vitamin D deficiency is also known to be associated with diffuse musculoskeletal pain. We studied the levels of vitamin $\mathrm{D}$ in patients of RA and its relation with disease activity.

\section{Materials and Methods}

The study is Hospital based cross-sectional and observational study. Patients were divided into case and control groups. Case group comprised of confirmed cases of rheumatoid arthritis and controls were normal population. Forty four patients of rheumatoid arthritis diagnosed according the 2010 revised criteria of the American College of Rheumatology (ACR) were included in the study. The study was carried out from October 2015 to October 2017. Patients of RA having chronic renal failure, systemic lupus erythematosus, diabetes mellitus, any systemic illness and patients on enzyme inducer drugs or on calcium and vitamin D supplements were excluded from study. Forty healthy control subjects were selected from general population who were age and sex matched and were free from any systemic illness. Informed consent was taken from all the study subjects. 
Vitamin D3 level was assessed by Vitamin D chemiluminescence in both case and control group . Vitamin D deficiency was defined as vitamin D level below $(20 \mathrm{ng} / \mathrm{ml})$, vitamin D insufficiency was defined as vitamin D level $(20-30 \mathrm{ng} / \mathrm{ml})$ and vitamin D sufficiency was defined as vitamin D level above $30 \mathrm{ng} / \mathrm{m} 1$ (Table 1). The vitamin D levels in cases and controls is compared using tests of significance by SPSS software.

Table 1 Classification of vitamin D deficiency

\begin{tabular}{|l|c|}
\hline NORMAL VALUE OF VITAMIN D & $>30 \mathrm{ng} / \mathrm{ml}$ \\
\hline VITAMIN D INSUFFICIENCY & $20-30 \mathrm{ng} / \mathrm{ml}$ \\
\hline VITAMIN D DEFICIENCY & $<20 \mathrm{ng} / \mathrm{ml}$ \\
\hline
\end{tabular}

DAS28 SCORE was calculated by assessment of no. of swollen joints (SW28), tender joints (TEN28), ESR values and patients global assessment of disability in last 7 days. The information was extracted from study subjects by predesigned and pretested questionaire.

\section{Calculation of DAS28 to assess severity of RA}

The DAS28 can be calculated by using the formula.

DAS28 $=0.56 \mathrm{X}$ sqrt (tender 28) $+0.28 \mathrm{X}$ sqrt (swollen 28) + 0.70 X in (ESR) + 0.014XGH

The DAS28 provides a number on a scale from 0 to 10 indicating the current activity of disease of rheumatoid arthritis patients. A DAS28 score above 5.1 means high disease activity whereas a DAS28 score below 3.2 indicates low disease activity. Remission is achieved by a DAS28 below 2.6.

The cases were then divided on the basis of disease activity into groups with low, moderate and high activity (Table 2).

Table 2 Disease activities according to DAS score

\begin{tabular}{|l|c|}
\hline DISEASE ACTIVITY & DAS SCORE \\
\hline LOW & $2.6-3.2$ \\
\hline MODERATE & $3.2-5.1$ \\
\hline HIGH & $>5.1$ \\
\hline
\end{tabular}

\section{Study Tools}

\section{History and Examination}

Detailed history was taken including history of duration of disease, remission and relapses, family history and past history. History of confounding factors including smoking and alcohol and other chronic medical illness.
Detailed musculoskeletal examination was done by:

Inspection

Palpation

Range of motion and strength assessment

\section{Statistical Analysis}

Data collected by predesigned and pretested questionaire was converted into tabulated form in MS EXCEL software and analysed by using tests of significance using SPSS 23 software. Data was analyzed statistically using Chi Square test, Students' unpaired t test and Analysis of variance (ANOVA) test. Significance was determined by $p$ value. $\mathrm{P}>0.05$ - non significant, $\mathrm{P}<0.05-$ significant and $\mathrm{P}<0.001$ - highly significant. Conclusions were drawn after comparing present result with previous result, vitamin D and RA, as well as the relationship between vitamin $\mathrm{D}$ and RA disease activity.

\section{Results}

4 patients of RA were excluded based on exclusion criteria. Out of 40 patients $11(27.5 \%)$ were males and 29(72.5\%) were females. The ratio of female to male was $2.7: 1$.

Maximun no. of cases belong to the age group of 35-45 yrs. Mean age of patients of RA was 41.08 \pm 7.35 years while the mean age of healthy controls was $43 \pm 6.4$ years. There was no significant difference among both group with regards to age and sex (P VALUE<.05).

Mean serum vitamin $D$ level of patients of RA was $(16.00 \pm 8.91 \mathrm{ng} / \mathrm{ml})$ while mean serum vitamin $\mathrm{D}$ level of healthy controls was (31.5 \pm $14.34 \mathrm{ng} / \mathrm{ml}$ ) and this difference was statistically significant $(\mathrm{p}<0.001)$. In our study $95 \%$ patients of RA were either vitamin D deficient or insufficient while among healthy controls vitamin D deficiency or insufficiency was seen in $50 \%$. This difference was statistically significant $(\mathrm{p}=<0.05)$. The prevalence of vitamin D deficiency and insufficiency in patients of RA is $62.5 \%$ and $32.5 \%$ respectively 
Relation of Serum Vitamin D Levels with ESR in RA Patients

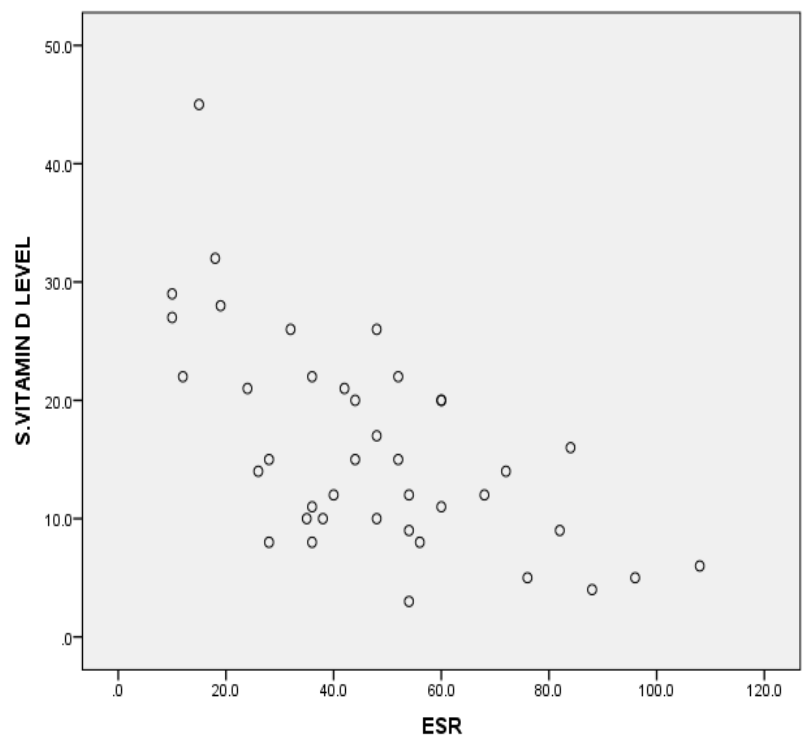

Serum vitamin D level and ESR are inversely correlated and this correlation was found to be statistically significant ( $\mathrm{p}$ value $<0.05$ ). The mean ESR levels were 27.175+_9.8. 77.5\% (31) patient had ESR value above 20 out of which $87 \%$ (27) were vitamin $\mathrm{D}$ deficient.

Table 3: Showing correlation of vitamin D level with ESR

\begin{tabular}{|l|c|}
\hline VITAMIN D LEVEL & ESR \\
\hline PEARSON COFFICIENT & -0.624 \\
\hline P VALUE & $<0.01$ \\
\hline
\end{tabular}

Relation of no. of tender joints in patients of RA with serum vitamin D level

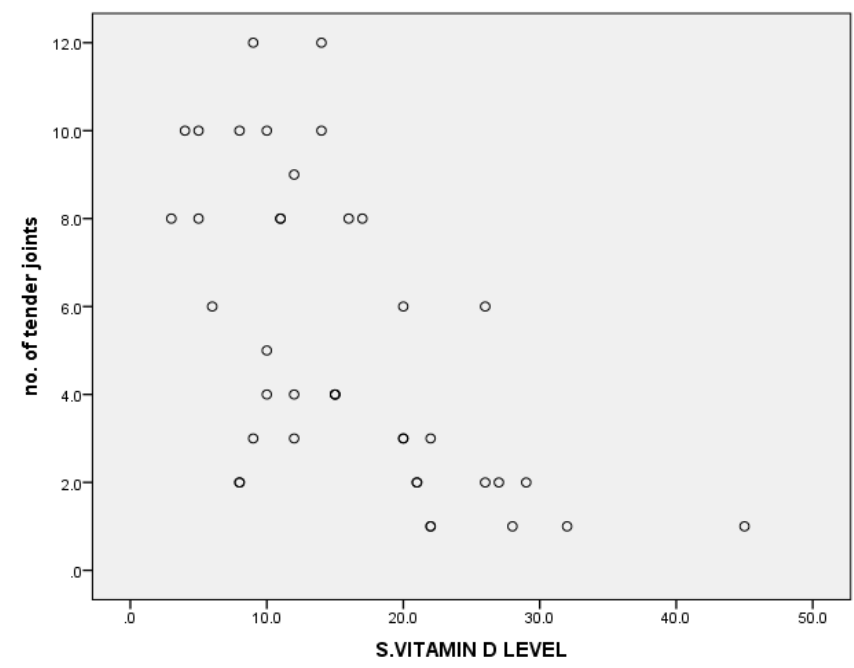

The no. of tender joints were more in patients with vitamin $\mathrm{d}$ deficiency. Cases with more than 3 tender joints had lower vitamin D levels

Table 4

\begin{tabular}{|c|c|c|c|}
\hline $\begin{array}{c}\text { NO. OF TENDER } \\
\text { JOINTS }\end{array}$ & $\begin{array}{c}\text { S.VITAMIN D } \\
<30 \mathrm{ng} / \mathrm{ml}\end{array}$ & $\begin{array}{c}\text { S.VITAMIN D } \\
>30 \mathrm{ng} / \mathrm{ml}\end{array}$ & TOTAL \\
\hline $0-3$ & 15 & 2 & 17 \\
\hline $03-10$ & 21 & 0 & 21 \\
\hline$>10$ & 2 & 0 & 2 \\
\hline
\end{tabular}

The mean no. of tender joints in cases was $7.6+5.2$ with $100 \%$ patient having vitamin D deficiency if tender joints were above 10 and $88 \%$ patient having vitamin $\mathrm{D}$ deficiency if tender joints were below 3 .

\section{Relation of no. of swollen joints with serum} vitamin d levels in RA patients

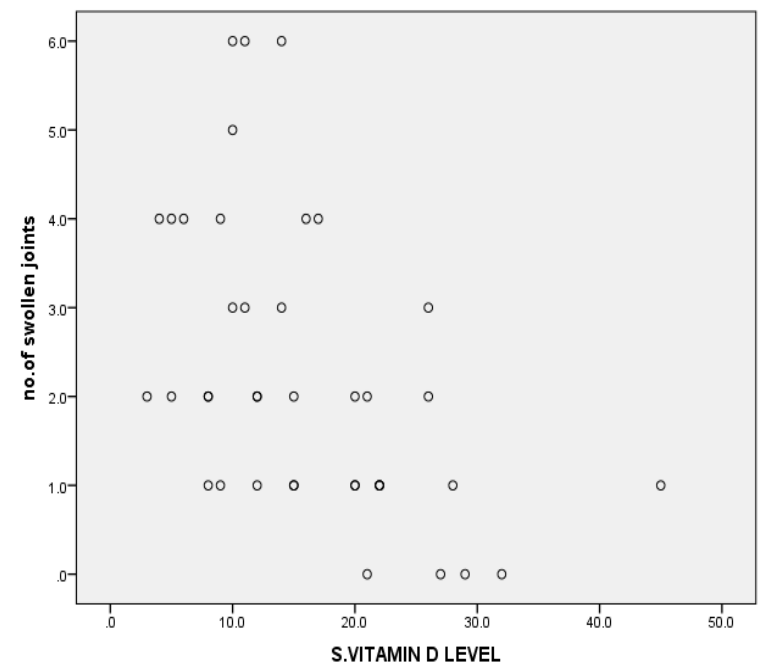

The no. of swollen joints were more in patients with vitamin D deficiency. Patients with swollen joints more than 3 had lower levels of vitamin D.

Table 5

\begin{tabular}{|l|c|c|c|}
\hline $\begin{array}{l}\text { NO. OF SWOLLEN } \\
\text { JOINTS }\end{array}$ & $\begin{array}{c}\text { S.VITAMIN } \\
\text { D }<30 n g / m l\end{array}$ & $\begin{array}{c}\text { S.VITAMIN } \\
\text { D }>30 n g / m l\end{array}$ & TOTAL \\
\hline $0-2$ & 24 & 2 & 26 \\
\hline $03-05$ & 11 & 0 & 11 \\
\hline$>5$ & 3 & 0 & 3 \\
\hline
\end{tabular}

Mean no. of SWOLLEN joints were $4.475+\_3.2$ with vitamin D deficiency in $100 \%$ patients having swollen joints more than 5 and in $92 \%$ of patients having swollen joints less than 2 . 
RELATION OF DISEASE ACTIVITY WITH SERUM VITAMIN D LEVEL

\begin{tabular}{|l|c|c|c|c|}
\hline DISEASE ACTIVITY & TOTAL CASES & VIT.D<30ng/ml & VIT.D>30ng/ml & MEAN VALUE OF VIT.D \\
\hline LOW & 6 & 4 & 2 & 30.5 \\
\hline MODERATE & 18 & 18 & 0 & 16.7 \\
\hline HIGH & 16 & 16 & 0 & 9.6 \\
\hline
\end{tabular}

The difference in disease activity with vitamin $\mathrm{D}$ level is found to be statistically significant ( $p$ value <.05). Patients with low disease activity had higher mean value of vitamin D as compared to patients with higher disease activity who had lower vitamin D levels. There were 6 patients of RA in low disease activity group (DAS 28 score < 3.2) and the mean serum vitamin $D$ level in this group was $30.5 \pm 9.81 \mathrm{ng} / \mathrm{ml}$

There were $18 \mathrm{RA}$ patients in moderate disease activity group (DAS 28 score $3.2-5.1$ ) and the mean serum vitamin D levels were 16.7 \pm 5.97 $\mathrm{ng} / \mathrm{ml}$. There were $16 \mathrm{RA}$ patients in high disease activity group (DAS 28 score $>5.1$ ) and the mean serum $25(\mathrm{OH})$ vitamin $\mathrm{D}$ level was $9.60 \pm 4.30$ $\mathrm{ng} / \mathrm{ml}$ patients $11(27.5 \%)$ are males and 29 $(72.5 \%)$ are females. The ratio of female to male was 2.7:1.

\section{Discussion}

The prevalence of vitamin D deficiency and insufficiency in patients of RA is $62.5 \%$ and $32.5 \%$ respectively in our study.

This is in contrast to study done by QURAISHI MK et al (2016) where prevalence was found to be $36 \%$ and $29 \%$ in respective groups ${ }^{[4]}$.

These results were also supported by the study done by RACKIEWIEZ A et al (2015). They reported that vitamin $\mathrm{D}$ deficiency is present in $76.5 \%$ of RA patients ${ }^{[7]}$. SHARMA et al in 2014 also reported that the Ninety percent of RA patients were either vitamin D deficient or insufficient and Mean serum vitamin D levels of RA patients was significantly low compared to healthy controls $(\mathrm{p}=0.009) .{ }^{[8]}$

Hong Q et al (2014) also reported that Serum level of $25(\mathrm{OH}) \mathrm{D}$ was markedly lower in the RA group than in the normal population ${ }^{[11]}$

There were 6 patients of RA in low disease activity group (DAS 28 score $<3.2$ ) and the mean serum vitamin D level in this group was $30.5 \pm 9.81$ $\mathrm{ng} / \mathrm{ml}$

There were 18 RA patients in moderate disease activity group (DAS 28 score $3.2-5.1$ ) and the mean serum vitamin $\mathrm{D}$ levels were $16.7 \pm 5.97$ $\mathrm{ng} / \mathrm{ml}$. There were $16 \mathrm{RA}$ patients in high disease activity group (DAS 28 score $>5.1$ ) and the mean serum 25(OH) vitamin D level was $9.60 \pm 4.30$ $\mathrm{ng} / \mathrm{ml}$. Patients with high disease activity had significantly lower vitamin D levels in comparison to patients with low or moderate disease activity $(\mathrm{p}<0.001)$. This result was supported by study done by sharma et al. They reported Vitamin D levels in high disease activity group was significantly low compared to vitamin D level in patients with low and moderate and low disease activity $(\mathrm{p}<.001)^{[1]}$

The vitamin D levels were negatively correlated with ESR ( $r=-0.624, \mathrm{P}$ VALUE $<0.05)$. The no. of tender and swollen joints were more in cases with lower level of serum vitamin D. The mean ESR values were higher in patients with high and moderate disease activity ( $\mathrm{p}$ value $<0.05$ ).

Our study results are in conjunction with study done by Kerr GS et al (2011), Hong Q et al (2014) and RACKIEWIEZ et al (2015).

Kerr GS et al (2011) also concluded that $25(\mathrm{OH})$ vitamin D deficiency, but not insufficiency, was independently associated with higher tender joint counts and highly sensitive CRP levels[12]. They also found that significant negative correlation between disease activity measured by DAS-28 score and serum vitamin D level which indicate that as the disease activity increases in RA patients which is a marker of increased inflammatory burden, vitamin D level falls.

Hong Q et al (2014) also reported that, 25(OH)D levels were significantly and negatively associated with clinical parameters of disease activity including swollen joint count, tender joint count, joint pain degree ${ }^{[11]}$ 
RACKIEWIEZ et al (2015) also reported that there was a negative correlation between $25(\mathrm{OH})$ D serum concentration and Disease Activity Score in 28 Joints in patients with active Vitamin D deficiency $^{[7]}$.

Our results are in contrast to study done by Rossini et al (2010) which showed that vitamin D deficiency is equally common in RA and healthy controls. ${ }^{[6]}$ These results are also in contrast to previous studies done by Turhanoglu et al (2011) which showed that vitamin D level of patients of RA was not significantly different from healthy controls $^{[10]}$.

Vitamin D deficiency is very common in patients of rheumatoid arthritis. Vitamin D deficiency or insufficiency is more common in rheumatoid arthritis in comparison to healthy controls and vitamin D deficiency, may be one of the causes leading to development or worsening of RA. As the inflammatory burden increases in rheumatoid arthritis, levels of vitamin D are reduced which shows immunomodulatoy activity of vitamin D. In rheumatoid arthritis disease activity measured by DAS-28 has negative correlation with serum vitamin D level.

\section{Conclusion}

Out of 40 patients $11(27.5 \%)$ are males and $29(72.5 \%)$ are females. The ratio of female to male was 2.7:1.

Maximun no. of cases belong to the age group of 35-45. Mean serum vitamin D level of patients of RA was $(16.00 \pm 8.91 \mathrm{ng} / \mathrm{ml})$ while mean serum

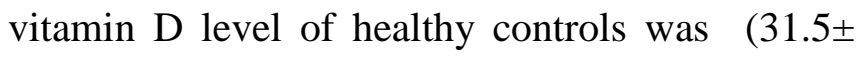
$14.34 \mathrm{ng} / \mathrm{ml}$ ) and this difference was statistically significant $(\mathrm{p}<0.001)$. In our study $95 \%$ patients of RA were either vitamin D deficient or insufficient while among healthy controls vitamin D deficiency or insufficiency was seen in $50 \%$. This difference was statistically significant $(\mathrm{p}=<0.05)$.

The prevalence of vitamin $\mathrm{D}$ deficiency and insufficiency in patients of RA is $62.5 \%$ and $32.5 \%$ respectively. We concluded vitamin D deficiency is highly prevalent in RA patients and is inversely related with disease activity of RA. So we advocate that Vitamin $\mathrm{D}$ should be supplemented adequately in RA patients.

\section{References}

1. Marwaha RK, Sripathy G. vitamin D and bone mineral density of healthy school children in northern India.

2. Nielen MMJ, van Schaardenburg D, van de Stadt RJ et al(2006): Vitamin D deficiency does not increase the risk of rheumatoid arthritis. Arthritis Rheum 11:3719-3724

3. Oelzner P, Muller A, Deschner F, Huller M, Abendroth K, Hein G, Stein G: Relationship between disease activity and serum levels of vitamin D metabolites and PTH in rheumatoid arthritis. Calcif Tissue Int. 1998, 62: 193-198.

4. Quraishi MK, Badsha H:Int J Rheum Dis. 2016 Apr;19(4):348-54.

5. Rheumatol Int. 2015 Mar;35(3):499-505.

6. Rossini M, Maddali Bongi S, La Montagna: Arthritis Res Ther. 2010;12 (6): $\mathrm{R} 216$

7. Raczkiewicz A, Kisiel B, Kulig M, Tłustochowicz W. J Clin :Rheumatol. 2015 Apr;21(3):126-30.

8. Sharma R, Saigal R, Goyal L, Mital P, Yadav RN, Meena PD, AgrawalA: Estimation of vitamin $\mathrm{D}$ levels in rheumatoid arthritis patients and its correlation with the disease activity. J Assoc Physicians India. 2014 Aug;62(8): 678-81.

9. Steinman L. A brief history of TH17, the first major revision in the $\mathrm{TH} 1 / \mathrm{TH} 2$ hypothesis of $\mathrm{T}$ cell-mediated tissue damage. Nat Med 2007;13:139-45.

10. Turhanoğlu AD, Güler $\mathrm{H}$, Yönden Z, Aslan F, Mansuroglu A, Ozer C : The relationship between vitamin $\mathrm{D}$ and disease activity and functional health status in rheumatoid arthritis. Rheumatol Int. 2011 Jul;31(7):911-4.

11. Hong Q, Xu J, Xu S, Lian L, Zhang M, Ding C : Associations between serum 
25-hydroxyvitamin D and disease activity, inflammatory cytokines and bone loss in patients with rheumatoid arthritis. Rheumatology :53(11):1994,2014.

12. Kerr GS, Sabahi I, Richards JS, Caplan, Cannon GW, Reimold: Prevalence of vitamin D insufficiency/deficiency in rheu matoid arthritis and associations withdisea seseverity and activity Rheumatol. 38(1): 53-9, 2011. 